\title{
Water Interception and Radical Reform Mathematical Models
}

\author{
Yuchen Huang \\ North China Electric Power University, Beijing, 102206 \\ alanncepu@foxmail.com
}

Keywords: Water interception; Radical reform; Mathematical models; Matlab

\begin{abstract}
In recent years, the city commissar adheres to the quality guidance and ecological lead. They regard the water environmental governance as an important content of creating a beautiful and livable Shenzhen. In order to achieve the goal, they energetically carry out the infrastructure construction of water conservancy; continuously strengthen the management of water affairs. The two kinds of measures given by the Shenzhen municipal government are "water interception" and "radical reform". Based on the statistical data of Shenzhen Bao'an district, we use Matlab to make function curves with the aid of related calculation formulas. Then we build the mathematical models of two different measures. Finally, we point out the advantages and disadvantages of these models and the promotion, hoping to help the government compare the effect of the sewage treatment.
\end{abstract}

\section{Background of the Question}

Now, the Shenzhen municipal government attaches great importance to ecological environment construction and water conservancy work. They plan to take a series of effective measures to ensure the full realization of the solemn commitment to the citizens: "Taking one year to get initial success, three years to eliminate black waterlog, five years to meet the minimum requirements, eight years to make the clear water and blue sky become bright urban cards of Shenzhen together."

What results in the water of Shenzhen Jiancheng district becoming black and smelly is sewage directly discharged into the river and sea. The two kinds of measures adopted by the municipal government mainly are "water interception" and "radical reform". "Water interception" means installing intercepted pipelines or boxes at the end of drain pipe network in the control area. After collecting the mixture of the rain and sewage water, we send it to the sewage plants. "Radical reform" means trying to establish the distribution system of rain and sewage in the first place. With two sets of pipe networks for collecting sewage and rainwater in the governance areas, the sewage enters waste handling facilities through sewage pipes and the rain directly enters the river through flood drainage channels.

The two measures both have advantages and disadvantages. In order to measure the effects of sewage treatment, we establish two mathematical models: the separate flow system model and combined sewer system model.

\section{Analysis of the Problem}

The separating sewer system means discharge of urban sewage and rainwater separately from the source. With two sets of pipe networks for collecting sewage and rainwater in the governance areas, the sewage enters waste handling facilities through sewage pipes and the rain directly enters the river through flood drainage channels. However, the rain directly entered into river has certain non-point source pollution. The sewage run-off system means installing intercepted pipelines or boxes at the end of drain pipe network in the control area. Nevertheless, when the rainfall is too large, it will make the treatment plants' sewage overflow caused by overload operation.

\section{Definition and Symbols}

The definition of symbols and formulas are as follows: 
Table 1

\begin{tabular}{|c|c|c|}
\hline Name & Symbol & Unit \\
\hline $\begin{array}{c}\text { The daily cod emissions of domestic pollution by combined system with } \\
\text { interception in sample }\end{array}$ & $\mathrm{L}_{\mathrm{c}}$ & $\mathrm{m}^{3} /$ day \\
\hline $\begin{array}{c}\text { The daily sewage treatment capacity of combined system with interception } \\
\text { facility in sample }\end{array}$ & $\mathrm{L}_{\mathrm{w}}$ & $\mathrm{m}^{3} /$ day \\
\hline The number of rainy days in the ith month & $\mathrm{d}(\mathrm{i})$ & day \\
\hline The sewage quantity of annual rain in a given area & $\mathrm{W}_{\mathrm{y}}$ & $\mathrm{m}^{3} /$ year \\
\hline Annual cod emissions of domestic pollution in a given area & $\mathrm{M}_{\mathrm{y}}$ & tons/year \\
\hline Surface runoff ( function) & $\mathrm{f}(\mathrm{t})$ & \\
\hline The cod pollution concentration of rain (function) & $\mathrm{g}(\mathrm{t})$ & \\
\hline The amount of average monthly rainfall in the ith month & $\mathrm{h}(\mathrm{i})$ & $\mathrm{m}^{3}$ \\
\hline Sewage treatment capacity of separate system & $\mathrm{L}_{\mathrm{fc}}$ & $\mathrm{m}^{3} /$ year \\
\hline The yearly cod emissions of domestic pollution in separate system & $\mathrm{L}_{\mathrm{fp}}$ & tons/year \\
\hline Sewage treatment capacity of interception system & $\mathrm{L}_{\mathrm{jc}}$ & $\mathrm{m}^{3} /$ year \\
\hline The yearly cod emissions of domestic pollution in interception system & $\mathrm{L}_{\mathrm{jp}}$ & tons/year \\
\hline Spilled overflow sewage quantity (function) & $\mathrm{m}(\mathrm{t})$ & \\
\hline The cod pollution concentration in interceptor (function) & $\mathrm{n}(\mathrm{t})$ & \\
\hline Sewage quantity in interceptor (function) & $\mathrm{w}(\mathrm{t})$ & \\
\hline The cod pollution concentration when dry & $\mathrm{p}(\mathrm{t})$ & \\
\hline The cod emissions of dry flow sewage(constant function) & $\mathrm{q}(\mathrm{t})$ & \\
\hline
\end{tabular}

\section{The Separate Flow System Model}

In this model, as far as we're concerned, the sewage treated by separate flow system is only from the urban waste water, while the rainwater is directly discharged into the river without treatment.

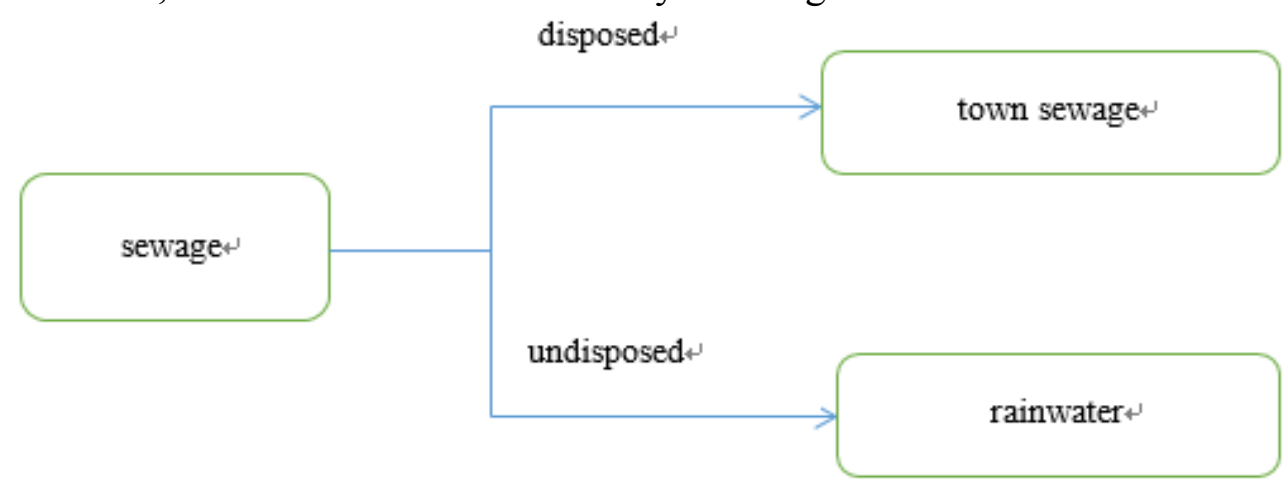

Figure 1

The formula of treated sewage is as follow:

$\mathrm{L}_{f c}=\mathrm{W}_{\mathrm{y}}$

The formula of sewage without treatment is as follow:

$\mathrm{L}_{f p}=\mathrm{W}_{\mathrm{y}}$

The numeration of separated sewer system in Shengzhen Bao'an District is as follow: 
Table 2

\begin{tabular}{|c|c|c|}
\hline Bao'an District & $\begin{array}{c}\text { The annual total sewage treatment } \\
\text { capacity }\left(\mathrm{m}^{3} / \text { year }\right)\end{array}$ & $\begin{array}{c}\text { Annual cod pollution } \\
\text { Emissions( tons/year) }\end{array}$ \\
\hline separate system & 179540000 & 9664.4 \\
\hline
\end{tabular}

\section{The Combined Sewer System Model}

In this system, we collect the mixture of the rain and sewage water at first. Then we send it to the sewage plants through intercepting pipes.

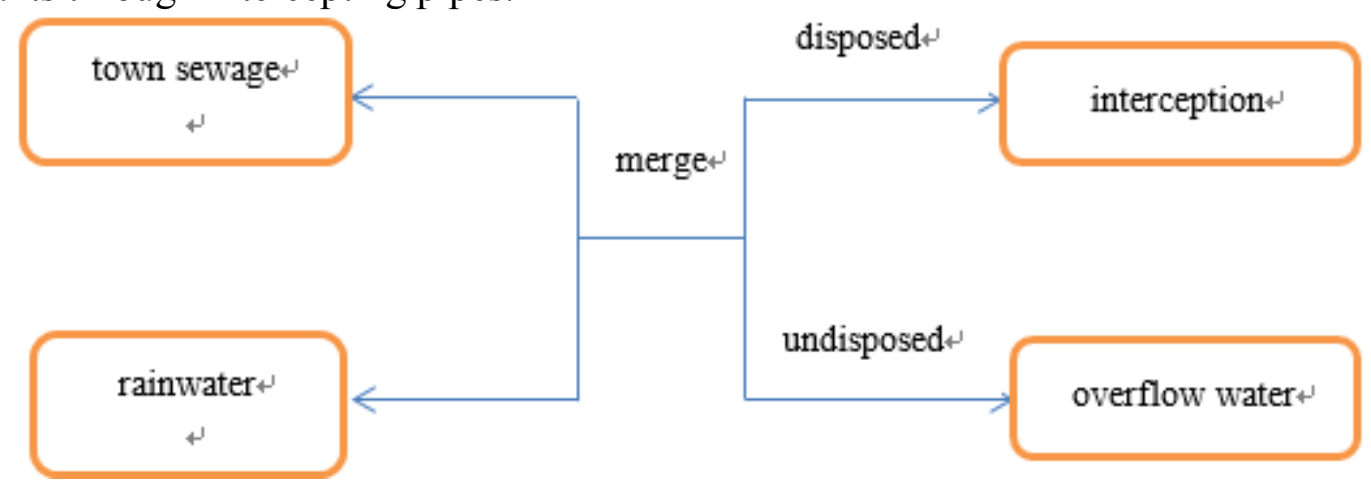

Figure 2

The situation of dry weather flow is as follow:

Table 3

\begin{tabular}{|c|c|}
\hline The discharged volume of residential sewage in Bao'an District $\quad\left(\mathrm{m}^{3} / \mathrm{s}\right)$ & 43.02998 \\
\hline Sewage concentration $(\mathrm{mg} / \mathrm{L})$ & 200 \\
\hline
\end{tabular}

That is to say: the surface runoff of sewage in intercepting pipes $=$ the surface runoff caused by rainfall + the sewage flow of dry weather. $w(t)=f(t)+q(t)$.

The functional image changing in time is as follow:

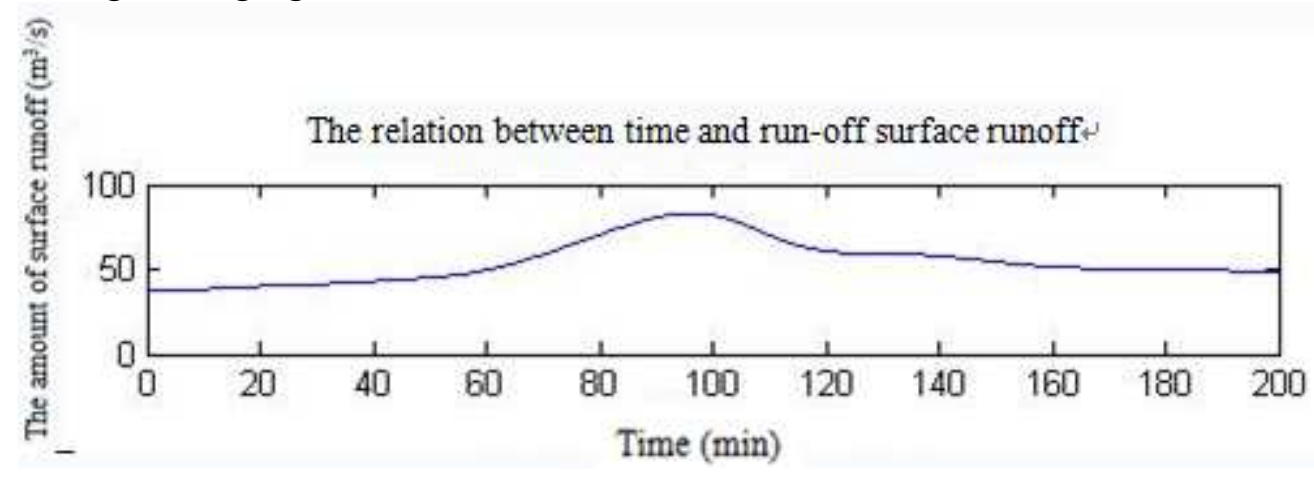

Figure 3

When the rainfall is relatively big, the flow through an intercepting pipe in per unit time is certain, so there will be a part of the sewage overflow. The water beyond the load of sewage treatment plants will not be processed and it will be directly discharged into the water container, which results in pollution. In order to quantitative evaluation of the overload caused by pollution, we will draw the load part of the above figure into the diagram alone.

According to the related data, we take the closure multiples of 1 .

We draw the functional image of the relation between time and run-off spilled water according to the above theories: 


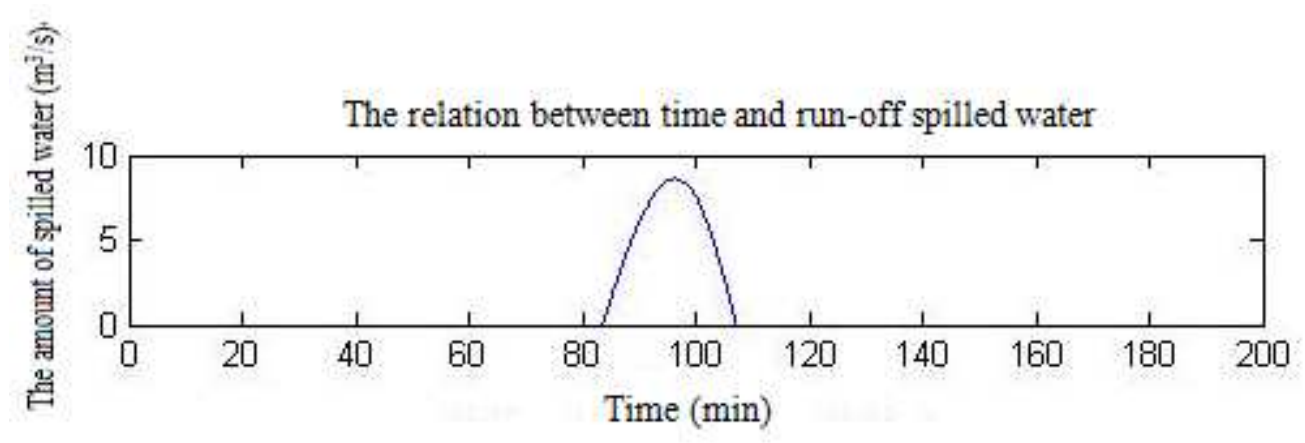

Figure 4

Next, we are about to calculate the run-off concentration of pollution. We use the formula:

$\mathrm{n}(\mathrm{t})=\frac{1}{w(\mathrm{t})} *[\mathrm{p}(\mathrm{t}) * \mathrm{q}(\mathrm{t})+\mathrm{g}(\mathrm{t}) * \mathrm{f}(\mathrm{t})]$

We draw the following figure using the above formula.

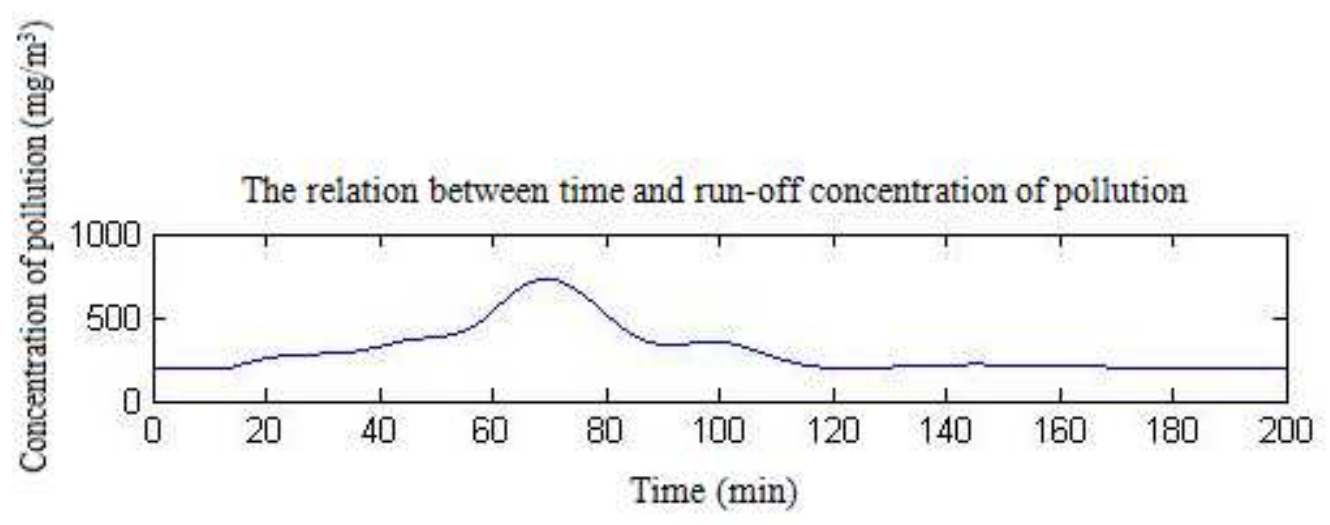

Figure 5

Then we multiply the amount of overflow water in each moment by pollution concentration at first. Second, we calculate the integral in $[0,200] \mathrm{min}$ in order to get the total pollution load caused by the overflowed water in the intercepting pipes from the rain, namely, the amount of COD pollution in the combined sewer system.

The above calculation is embodied in the following formula:

$$
\mathrm{L}_{j p}=\int_{t_{1}}^{t_{2}} \mathrm{~m}(\mathrm{t}) * \mathrm{n}(\mathrm{t}) \mathrm{dt}
$$

We think in the combined sewer system model, the COD pollution load caused by overflowed water in sample days is directly proportional to the rainfall of the day. We calculate the total amount of rainfall according to Bao'an district's rainfall days in every month and the average amount of rainfall in every rainy day. Then we proportionately calculate the numerical value and COD pollution load that we already found out so as to get the total pollution load of each month caused by the overflowed water in the intercepting pipes. The total pollution load of the every month and COD pollution load for the whole year are as the following formula:

$$
\mathrm{L}_{j p}=L_{w} * \sum_{i=1}^{12} \frac{h(\mathrm{i}) * \mathrm{~d}(\mathrm{i})}{J}
$$

Through the analysis, we come to a conclusion that the amount of the treated sewage in the combined sewer system and the overflowed sewage is equal to sewage flow in the intercepting 
pipes. As a result, for the amount of treated sewage in combined sewer system, we can use the following formula:

$$
\mathrm{L}_{j p}=L_{c} * \sum_{i=1}^{12} \frac{h(\mathrm{i}) * \mathrm{~d}(\mathrm{i})}{J}
$$

The calculation of combined sewer system in Shenzhen Bao'an district is following:

Table 4

\begin{tabular}{|c|c|c|}
\hline Bao'an District & $\begin{array}{c}\text { The annual total sewage treatment } \\
\text { capacity }\left(\mathrm{m}^{3} / \text { year }\right)\end{array}$ & $\begin{array}{c}\text { Annual cod pollution } \\
\text { Emissions( tons/year) }\end{array}$ \\
\hline combined sewer system & 1529873300 & 230.39 \\
\hline
\end{tabular}

\section{Promotion of the Model}

Because the algorithms used in this model are kind of fundamental, the model can be supplemented by other advanced drainage system model. For example, if we get the detailed situation of surface soil, rivers, lakes, rainfall and urban land utilization in the area, we can use the most advanced water management model SWMMH software to calculate the surface runoff and pollution situation of every day. In this way, the calculation of sewage and pollution produced by annual rainfall becomes more accurate. At the same time, if we get the detailed arrangement of sewage pipes in that area, we will calculate the exhaust pipes' sewage discharge and pollution concentration with the help of SWMMH, which makes the results more accurate. What's more, it will be more convenient to calculate the cost of pipelines in this way.

\section{References}

[1] Ye Zhihui, Zhao Jianmei. Analytical methods concerning the scale of initial rainfall interception in cities [J]. China Rural Water and Hydropower, 2011(9):63-65.

[2] Li Jiake, Li Yajiao, Li Huaien.Study on the calculation method for urban surface runoff pollution load [J].Journal of Water Resources and Water Engineering, 2015(1)

[3] Chen Xiaolong, Zhao Sidong, Zhao Dongquan, etc. Introduction of digital water simulation system, China Water \& Wastewater, 2015(1).

[4] Lin Jiasen. Study on interception factor in urban wastewater treatment [J]. Water \& Wastewater, 2004, 30(11):39-42.

[5] Wang Shumei, Wang Baozhen , Cao Xiangdong, etc. Discussion on Chinese urban drainage system[J]. China Water and Wastewater, 2007, 23(12):16-21.

[6] Zhang Chao, Jiang Yinghe. Optimization of interception ratio in combined sewer[J], Chinese Journal of Environmental Engineering, 2015, 9(6):2771-2776.

[7] $\mathrm{Xu}$ Zuxin, Wang Weigang, Li Huaizheng, etc. Treatment technique of combined sewer overflows [J].Environmental Engineering, 2010(s1):153-156.

[8] Wang Hongfang. Analysis on water radical action in Shenzhen[J]. Journal of Green Science and Technology. 2010(8):125-126.

[9] Gong Zheng, He Wenyuan, Wei Xingyao, etc. Analysis on area pollution model [J]. Southwest Water \& Wastewater, 2012(6):59-66.

[10] Xiao Sufen, Sun Wenchu. Influence and countermeasures of reservoir sewage interception in shenzhen[J]. Guangdong Water Resource and Hydropower, 2000(2):11-13 